\title{
Social Impacts of Transport: Literature Review and the State of the Practice of Transport Appraisal in the Netherlands and the United Kingdom
}

\section{Karst T. Geurs, Wouter Boon \& Bert Van Wee}

To cite this article: Karst T. Geurs , Wouter Boon \& Bert Van Wee (2009) Social Impacts of Transport: Literature Review and the State of the Practice of Transport Appraisal in the Netherlands and the United Kingdom, Transport Reviews, 29:1, 69-90, DOI: 10.1080/01441640802130490

To link to this article: https://doi.org/10.1080/01441640802130490

曲 Published online: 26 Nov 2008.

Submit your article to this journal $₫$

山ll Article views: 2930

Q View related articles ¿

4 Citing articles: 79 View citing articles 


\title{
Social Impacts of Transport: Literature Review and the State of the Practice of Transport Appraisal in the Netherlands and the United Kingdom
}

\author{
KARST T. GEURS*, WOUTER BOON** and BERT VAN WEE† \\ *Netherlands Environmental Assessment Agency, Bilthoven, The Netherlands; **Copernicus \\ Institute for Sustainable Development and Innovation, Utrecht University, Utrecht, The \\ Netherlands; +Delft, University of Technology, Delft, The Netherlands
}

(Received 17 May 2007; revised 17 December 2007; accepted 14 April 2008)

\begin{abstract}
Transport appraisals in European countries increasingly address three dimensions of sustainability-economic, ecological and social. However, social impacts of transport have been underexposed in (ex-ante) transport project appraisal, at least in the Netherlands. Firstly, this article presents a theoretical framework describing the relationships between determinants of social impacts of transport; it also provides a definition and categorization of those impacts. Secondly, the article reviews the state of the practice of national transport project appraisal in the Netherlands and the United Kingdom. The article shows that social impacts of transport investments can take on many forms and their levels of importance may vary widely, in project appraisal. The UK transport appraisal guidance includes a spectrum of social impacts through quantitative and qualitative assessments that is broader than the Dutch appraisal guidance. However, it does not cover the full range as identified in the literature. This holds, in particular, for the temporary impacts of transport investments, health impacts, social cohesion, the distribution and accumulation of impacts across population groups and social justice. All in all, it can be concluded that there is a long way to go before social impacts of transport projects are completely included in appraisals, in a way that allows us to compare them to economic and ecological effects.
\end{abstract}

\section{Introduction}

In the 1990s, the World Bank was one of the first institutions to develop an appraisal framework to assess sustainability impacts of specific funding proposals. It covered three sustainability dimensions: economic, ecological and social (Serageldin and Steer, 1994). In several countries, these three dimensions are increasingly addressed in transport policy appraisal, as well. The European Commission, for example, now requires impact assessments of major legislative 
and policy-defining initiatives, including those related to transport, incorporating in-depth analyses of potential impacts on the economy, society and the environment. In the Netherlands, cost-benefit analyses (CBAs) and environmental impact assessments (EIAs) are required for investments in infrastructure (for a review of the Dutch experience see Annema et al., 2007). However, the social impacts have remained underexposed in (ex-ante) transport policy appraisal, at least in the Netherlands, despite the fact that social equity effects (the distribution of 'costs' and 'benefits' among population groups) often receive more public and political attention than the total economic benefits estimated in CBAs.

The major difficulty in including social impacts in transport policy appraisal is that they can take on many forms, some of which are particularly difficult to estimate with any precision. Perceptions of the relative importance of different sorts of social impacts may also vary widely: perhaps, in part, because relatively little work has been done to develop methods, tools and techniques to rigorously estimate probable social impacts of transport changes (Forckenbrock et al., 2001). However, ignoring social impacts in ex-ante assessments of infrastructure projects would suggest that only economic and environmental impacts are important, while the recognition of the importance of social impacts is increasing. One of the difficulties of including social impacts in transport policy appraisal is that, often, no clear distinction can be made between social, ecological and economic impacts. In general, ecological impacts merely focus on receptors, such as flora and fauna, whereas social and economic impacts concentrate on human beings. For instance, air pollution, noise and climate change affect flora and fauna, as well as human beings, Therefore, they have both social and ecological impacts (and sometimes economic impacts, as well). The distinction between economic and social impacts is often pragmatic. Economic impacts included in transport appraisal focus typically on (the valuation of) changes in travel times and related consumers' surplus, changes in employment and business activity and earnings, whereas social impacts focus on changes in social patterns, social problems and lifestyles (Fischer, 1999). ${ }^{1}$ Furthermore, economic impacts are often analysed at the macro level, while social impacts are analysed at the individual (or local) level.

In this article, a theoretical framework for evaluating social impacts of transport projects is presented first, along with an overview and categorization of social impacts based on this framework, as found in the literature. Second, the inclusion is examined of social impacts in the state of the practice transport policy appraisal guidelines, for the Netherlands and the United Kingdom.

Both countries have comprehensive guidelines for transport policy appraisal and much experience in applying them in practice. A review of national appraisal practices in EU25 Member States and Switzerland revealed that the Netherlands and the United Kingdom are among the leading EU countries in terms of standardization and coverage of effects included in appraisal guidelines (Odgaard et al., 2005). Many other countries outside the EU, such as Australia, Japan and Taiwan also have appraisal guidelines or rules for transport infrastructure project appraisal (Tavasszy et al., 2005).

This article focuses on determining (the categories of) impacts and identifying voids in the state of the practice appraisal guidelines for social impacts, rather than comparing evaluation methods. It is not aimed at giving a review on the magnitude of categories of impacts. Note that transport appraisal is typically carried out as part of an overall decision-making process, which also involves consultation with and participation by the general public. Although public involvement is 
considered relevant in discussing social impacts, this article is only concerned with the transport appraisal process. The article aims to overview the current situation rather than the developments over time. Finally, further research will be indicated for improving the social impact appraisal of transport projects.

Having set the stage, the article will go on to define social impacts and a theoretical framework for the relationship between the transport system and social impacts, followed by a categorization of these impacts. Next, the focus shifts to the treatment of social impacts in the Dutch and the UK national transport infrastructure appraisal practices. Finally, conclusions are drawn, followed by a discussion and a description of directions for future research.

\section{Theoretical Framework}

\section{Defining Social Impacts of Transport}

Defining social impacts in general, and of transport in particular, is not an easy task. Stating that social impacts include all impacts on people is too broad a definition, but a limitation to "demographic changes, job issues, financial security and impacts on family life", issues often considered in environmental impact assessments (IAIA, 2003) is too narrow. In this article, social impacts of transport are defined as changes in transport sources that (might) positively or negatively influence the preferences, well-being, behaviour or perception of individuals, groups, social categories and society in general (in the future). Here, transport sources are defined as a movement and/or (potential) presence of vehicles using infrastructure or merely the presence of infrastructure itself.

The definition of social impacts is rather broad and implies an overlap with economic and ecological impacts. A broad definition is preferred, in this case, to avoid the risk of ignoring impacts that might be considered to be social, as well as economic or ecological. Thus, transport emissions affecting human beings are labelled as social impacts as a result of this definition. Other definitions might categorize such an impact under 'ecological impacts'. Also, a distinction needs to be made between an 'economic impact' and an assessment of impacts in monetary terms. An impact can, at the same time, be a social or ecological impact and be expressed in monetary units. The article does not consider this definition to be the only useful one, and realizes that other definitions may be as helpful to researchers and policymakers. However, regardless of the definition, to avoid double counting in evaluations such as CBAs and multi-criteria analyses (MCAs), a clear choice needs to be made on the categorization of effects and impacts. Each impact should, of course, be included only once.

Figure 1 presents the analysing process of the chain of impacts with special attention to differences between social groups. ${ }^{2}$ In this article, the terms 'social differences' and 'social (in)justice' are used, rather than 'equity' and social (or environmental) justice, terms which are more common in the academic literature (e.g. Khisty, 1996; Burton, 2000; Stephens and Bullock, 2002). Distinguishing between 'social differences' and 'social (in)justice' has the advantage of separating judgement and actions, and objectivity and subjectivity. This can help decision-makers and analysts to distinguish between different types of tasks: analysts need to uncover social differences on an objective basis, while decision-makers need to decide whether they should attach a subjective injustice tag on social differences, based on what they think is unjust. 


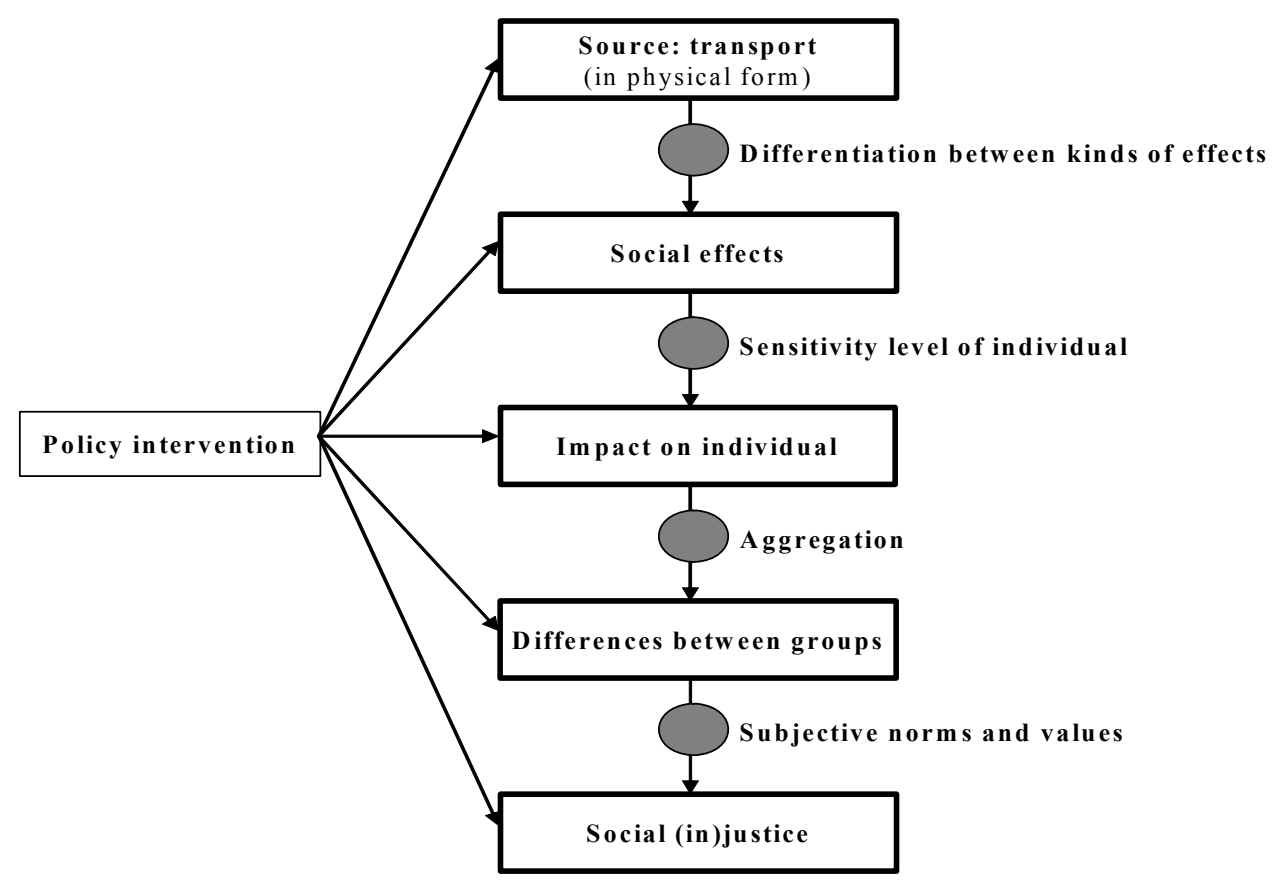

Figure 1. Specification of the source-effect-impact-receptor chain for social impacts of transport: the receptor part consisting of 'impacts on individual', 'differences between groups' and 'social (in)justice'

The different elements shown in Figure 1 are outlined below.

(1) Source: the existence and use of transport systems leads to physical effects, for example, the presence of noise, local air pollution and traffic in urban areas.

(2) Social effects: effects that change preferences, behaviour and/or perception of society, social categories and groups within this society and of individuals. For example, local air pollution can (potentially) change the way people perceive their neighbourhood environment.

(3) Impact on individuals: all the social effects (including those on society as a whole) can be reduced to the individual level. Here, effects must be distinguished from impacts. Analogous to epidemiology, individuals have their own sensitivity levels with respect to social effects. If an effect exceeds this level, it has an impact on these individuals. Thus, a social effect turns into a social impact (Lichfield, 1996). There are individual differences in the sensitivity to social effects. For instance, some individuals might be more sensitive to poor air quality than others, because they suffer from respiratory diseases, such as asthma. Sensitivity not only relates to 'objective' responses, but it can also be subjective, as in a sensitivity to noise.

(4) Differences between groups in society: identifiable groups of individuals can serve as units of analysis in impact assessments and policy intervention, since groups are easier to target through policy measures than individuals. Effects can be distributed across space, time and over social groups. Population groups are often distinguished by three indicators: social differences (for instance, gender and age), economic differences (income) and spatial differences (geographical) (Jones, 2001; Litman, 2002). 
(5) Social (in)justice: if social differences are unacceptable according to the values and standards of society, they are labelled a social injustice, which is a subjective and often political decision. Several theories or approaches of justice, documented in the literature, can be used in the decision-making process. Applications of different theories of social justice result in a different distribution of the net benefits to socio-economic groups and, thus, result in different conclusions (Khisty, 1996; PROPOLIS, 2003).

(6) Policy intervention: when social impacts, differences between groups or the level of social justice are identified, policymakers and politicians can take mitigating action, especially if the benefits exceed the costs.

\section{A Conceptual Model for the Factors Determining Social Impacts of Transport}

Figure 2 presents a conceptual model to describe the main categories of determinants for social impacts and their relationships. Essentially, the model is based on earlier conceptual models by Van Wee and Van der Hoorn (2002) and Geurs and Van Wee (2004a). The figure shows that social impacts are influenced by three categories: people, transport and land use. Determinants related to people can be grouped as follows: individuals and household characteristics (in terms of age, gender, ethnicity, number of workers in a household, etc.); people's opportunities and assets (e.g. income and educational level, car ownership); people's abilities (e.g. physical condition, ability to drive a car) and people's needs, attitudes and preferences (e.g. a status-seeking work and car-oriented lifestyle versus an urban/cultural public transport-oriented lifestyle). Transport determinants include (1) location and characteristics of the transport infrastructure (e.g. speed limit, number of lanes, design, travel costs, level of comfort, security) and the availability and quality of transport services (e.g. public transport time tables), and (2) transport volumes by vehicle type (e.g. car/lorry, technical characteristics of vehicles such as fuel economy, and compliance with emission standards). Also included is the distribution over space and time. Land-use determinants include the amount, quality and spatial distribution of activities and facilities (e.g. work, shops, social and health facilities, recreational areas), and the restrictions on capacity and availability (e.g. number of hospital beds available, opening hours of shops).

The three categories of determinants (people, transport and land use) are mutually dependent. For example, higher incomes of individuals will result in increased car use, and better roads might influence travel preferences. Activity locations might have consequences for travel demands, whereas the transport system affects land use. Certain characteristics influence the locations where people participate in activities, and the quality of residential areas could have an impact on people's preferences. The social environment may also interact with the different categories of determinants. McDonald (2007), for example, shows that the level of neighbourhood cohesion has a statistically significant effect on whether children walk to school; parents are more likely to let their children walk when they live in neighbourhoods where adults trust their neighbours.

Thus, social impacts of transport are caused by a multiplicity of factors, which might also reinforce each other. For example, inadequate transport to particular services or activities may prevent access to key local services or activities, such as jobs, and learning and healthcare, which, in turn, could reinforce social exclusion of particular groups. This is illustrated by a research in the UK, which suggests 


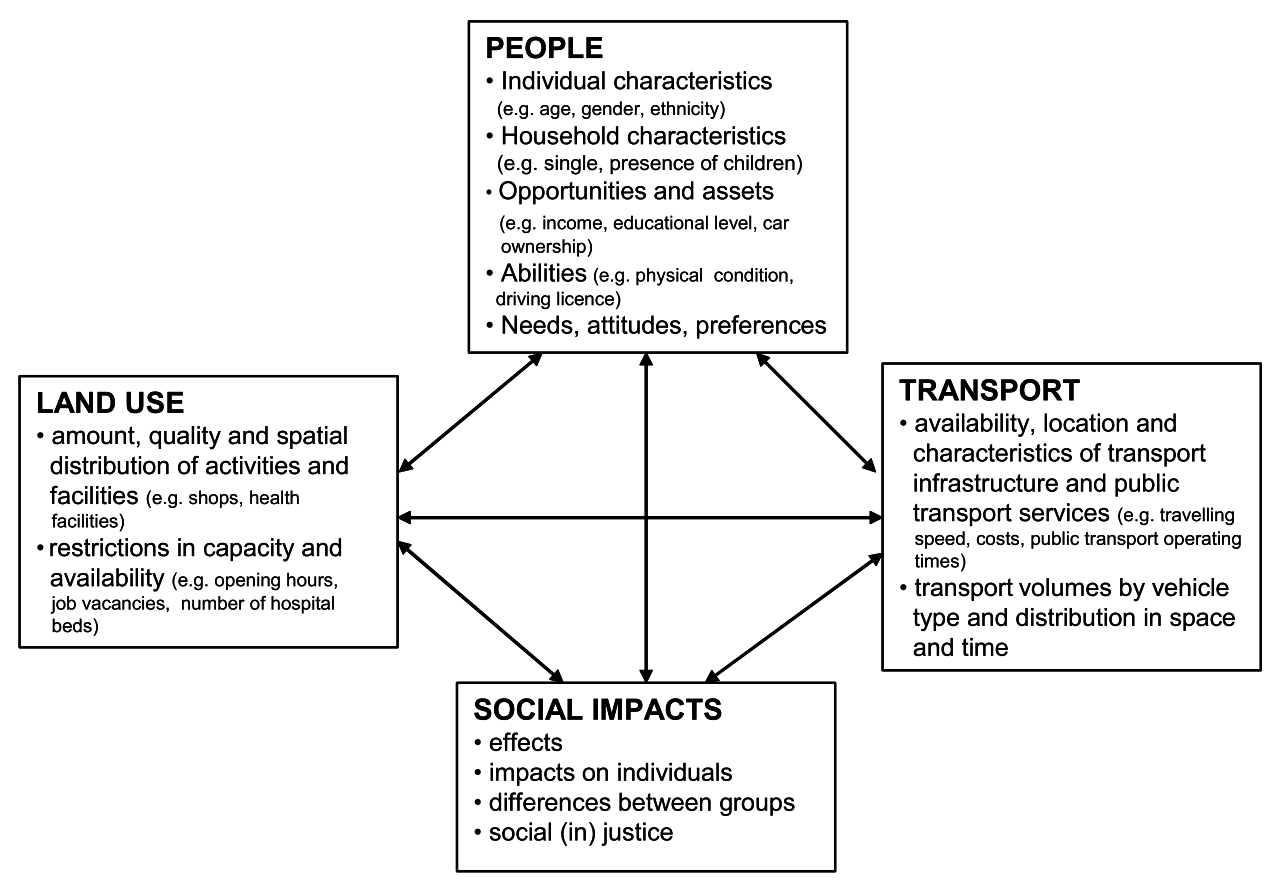

Figure 2. Conceptual model for the factors affecting social impact of transport

that about $40 \%$ of job-seekers in the UK reported transport (lack of personal transport or poor public transport) to be a crucial barrier to getting a job, and over 1.4 million people indicated that they have missed, turned down or chosen not to seek medical help because of transport problems (Social Exclusion Unit, 2003). These problems may vary according to type or area (e.g. urban or rural) and for different groups of people (such as disabled people or families with young children).

Figure 2 also leads to the conclusion that time is relevant to the occurrence of social impacts. In addition to primary impacts that occur immediately after a change in the system, such a change could also have secondary or even tertiary impacts. Changes in the transport system, for example, can affect land use in the long run, or affect people's preferences. In the literature, such effects are generally recognized by the interaction between land use and transport and related landuse/transport interaction models (e.g. see the contributions in the 2004 special issue of the European Journal of Transport and Infrastructure Research on Land useTransport interaction modelling, vol. 4, no. 3).

\section{Categorizing Social Impacts of Transport}

The social impacts of transport can take on many forms. Overviews of possible social impacts of transport are given, for example, by Finsterbusch (1980), Appleyard (1986), De Boer (1986), N. Lichfield and D. Lichfield (1992), Adams (2000) and Forckenbrock et al. (2001). These authors show a high diversity in the range of social impacts of transport. Moreover, perceptions vary, of the relative importance of some of the different types of social impact categories. This article presents a comprehensive categorization of the social effects of transport, based on the source-effects-impacts-receptor chain (Figure 1), along with the conceptual 
Table 1. Categorizing social impacts by source and levels of human needs

\begin{tabular}{|c|c|c|}
\hline Theme & Sub-themes & Impact \\
\hline \multirow[t]{7}{*}{ Presence of infrastructure } & \multirow[t]{3}{*}{ Structurally } & Visual quality \\
\hline & & Historical/cultural resources \\
\hline & & Severance/social cohesion \\
\hline & \multirow[t]{4}{*}{ Temporarily (construction) } & Noise nuisance \\
\hline & & Barriers and diversions \\
\hline & & Uncertainty of construction \\
\hline & & Forced relocation \\
\hline \multirow[t]{2}{*}{ Presence of parked vehicles } & & Visual quality \\
\hline & & Use of space \\
\hline \multirow{5}{*}{$\begin{array}{l}\text { Presence of transport facilities, } \\
\text { services and activities }\end{array}$} & \multirow[t]{4}{*}{ Transport facilities } & Availability and physical access \\
\hline & & Level of service provided \\
\hline & & $\begin{array}{l}\text { Transportation choice/option } \\
\text { values }\end{array}$ \\
\hline & & Cultural diversity \\
\hline & Land use & $\begin{array}{l}\text { Access to spatially distributed } \\
\text { services and activities }\end{array}$ \\
\hline \multirow[t]{6}{*}{ Traffic (movement of vehicles) } & \multirow[t]{4}{*}{ Safety } & Accidents \\
\hline & & Averting behaviour \\
\hline & & Safety perceptions \\
\hline & & Public safety (dangerous cargo) \\
\hline & \multirow[t]{5}{*}{ Environment } & Noise levels, nuisance \\
\hline & & Soil, air and water quality \\
\hline \multirow[t]{3}{*}{ Travel (movement of people) } & & Intrinsic value, journey quality \\
\hline & & Physical fitness \\
\hline & & Security \\
\hline
\end{tabular}

model presented earlier (Figure 2). The following sources are distinguished and described below: (1) presence of infrastructure; (2) presence of (parked) vehicles; (3) presence of transport facilities; (4) movement of vehicles (traffic); (5) travel; and (6) land use. Table 1 gives an overview of related impacts.

\section{Presence of Infrastructure}

The mere presence of transport infrastructures (roads, railway lines, waterways, etc.) may affect the quality of the physical environment. This applies to, for example, visual quality, light pollution and people's perception of the environment or neighbourhood, aesthetics and quality of life. One particular aspect is the effect of infrastructure on the human-induced historical environment, such as buildings of architectural or historical significance, or archaeological sites. Furthermore, new or existing transport schemes, such as roads or railways, can have detrimental social impacts on communities (severance). James et al. (2005) review empirical and theoretical literature on severance and conclude that it can have a physical dimension (e.g. reduced accessibility to key services, such as health, food, shopping), a psychological dimension (e.g. traffic noise or road safety fears) and a social dimension (e.g. some studies have suggested that heavy traffic volumes dividing local communities reduce the amount of social interaction with neighbours, e.g. Appleyard, 1981; Social Exclusion Unit, 2003). In the case of local 
roads, severance or cohesion effects are obviously also determined by the traffic levels on the roads, they are positioned here to avoid repetition. Note that transport systems not only create barriers to social interaction and cohesion, but also enhance social inclusion in terms of access to the system itself, or to the level of service provided. This effect is included in the different 'access' indicators.

The construction phase of transport infrastructure may also generate temporary effects, for example, noise nuisance, barriers and diversions that cause congestion and detours. Deciding on and pointing out a location for infrastructure also leads to uncertainty for local residents. For example, will residents be forced to relocate? If they stay, will the living conditions remain reasonable? Uncertainty may lead to psychosocial impacts, fear, aggression, annoyance and discomfort (Marx, 2002).

\section{Presence of Parked Vehicles}

Parked vehicles dominate large areas of the open space; they affect the visual quality of the physical environment and reduce the possibility of street activities. In the literature, high densities of parked vehicles are associated with higher risks of child pedestrian injuries (e.g. Agran et al., 1996). The danger in and perceived attractiveness of living surroundings are negatively associated with the time that children (are allowed to) play outside and with their social development (Hüttenmoser and Meierhofer, 1995; WHO, 2000).

\section{Presence of Transport Facilities, Services and Activities}

A number of effects are related to the presence of transport facilities (including transport infrastructure). Transport facilities allow people to get to spatially distributed destinations, such as for jobs, food, health and social services, as well as visiting family and friends. The concept of 'accessibility' is defined here as the extent to which the land use and transport systems enable (groups of) individuals to reach activities or destinations by means of a (combination of) transport modes (Geurs and Van Wee, 2004b). Accessibility, given individual characteristics, is determined by several components. The first one is the physical component: the availability and physical access to transport facilities affects accessibility, for instance, the availability of a vehicle for private use and access to public transport facilities for physically, economically or socially disadvantaged people. The component is generally ignored in ex-ante assessments.

The second component to affect accessibility is the level of service provided by the system, for instance, in terms of travel time, costs and comfort. Note that valuing travel time savings (the second component) is the standard in cost-benefit analysis. Such benefits are partly social and partly economic.

The third component, the spatial distribution of services and activities, and their characteristics (e.g. spatial and temporal constraints), affect people's level of access to key local services or activities, such as jobs, shops and health services. Transportation facilities offer choices of different routes or modes of travel at different times of the day. People may value having these travel options, even if they never actually use them. In the literature, the concept of option value is used to describe people's willingness to pay for the continued availability of a transport facility, to preserve the option of using this facility in the future (for an overview see Geurs et al., 2006; Laird et al., 2006). For example, car owners may 
value having public transport service 'stand-by' for unexpected situations in which they cannot drive or when their cars are not available. As a social impact, transport option values are likely to play a role when transport modes or transport infrastructures are substantially improved or deteriorated (such as opening or closing bus or rail services in sparsely populated areas).

A final issue related to the presence of transport facilities is the potential impact on cultural diversity. The opening of transport facilities, for instance, connecting remote areas to urbanized areas to benefit large-scale tourism in Third World countries, may have such an impact.

\section{Traffic}

A number of social effects are related to the movement of vehicles along a piece of infrastructure. The first kind of traffic-related social impact is related to transportation safety. In basic terms, two types of safety are relevant: the safety of people who use the transportation facility (travellers) and the safety of people whose activities place them in proximity to the facility (public), for example at accidents involving freight transport with dangerous cargo. Not only the number of traffic accidents, casualties or fatalities is relevant, but so is the perception of safety: if people do not feel safe this may affect their travel behaviour, perceptions and psychosocial well-being. Recent research, for example, indicates that a high main road density and exposure to traffic in the immediate neighbourhood amplifies perceived traffic stress and potential health effects (general health status, depressive symptoms) (Song et al., 2007).

The second type of traffic-related social impact has its effect on health, and results from traffic-related air pollution and noise. Traffic-related air pollution $\left(\mathrm{PM}_{10}, \mathrm{NO}_{2}, \mathrm{CO}\right.$ and ozone) leads to an increased risk of death and diseases as a result of respiratory problems, cardiovascular afflictions and forms of cancer (WHO, 2000). Long-term exposure to noise from traffic may have health impacts, such as noise nuisance, sleep disturbance, lowered concentration and problem-solving capability, and it may increase stress, blood pressure and aggression. A third traffic-related social impact is people's annoyance with busy traffic: even if cars would be silent, clean and safe, people would be annoyed by (heavy) traffic. A fourth traffic-related social impact is related to 'averting behaviour'. Particular population groups (e.g. children, elderly and asthma patients) may show such behaviour because of accident risks or air pollution. For example, they abstain from outdoor (sport) activities during a summer day with high ozone concentration, and children might not be allowed to play along busy streets. Lucas (2006) states that, for children, one of the biggest social changes in the last 50 years in the UK has been their parent's unwillingness to allow them to be alone outside, unsupervised, for fear of accidents or assaults. McMillan (2007) also reports a dramatic mode shift in school travel in the USA, from walking and bicycling to travelling by car, in the past few decades. It also shows, in a case study, that the travel behaviour of primary children going to schools in California is explained by several factors, including perceptions of neighbourhood safety and traffic safety, household transportation options, social/cultural standards and urban form. In the Netherlands, the share of walking and bicycling in primary school travel has remained quite highcurrently, only $15 \%$ of primary age children are taken to school by car. However, traffic safety was reported to be the second most important reason for 
car use, preceded only by the home-to-school travel distance (Van der Houwen et al., 2004).

\section{Travel}

The final category of effects refers to travelling itself. Firstly, there is evidence that travel has an intrinsic value resulting from psychological need or motivation, such as the enjoyment of moving (including the enjoyment of speed), curiosity or information seeking (Choo et al., 2005). There is a growing body of literature, which shows that travel time is experienced as something positive; some commuters seem to enjoy the commuting time in itself (e.g. Redmond and Mokhtarian, 2001; Jain and Lyons, 2008). Travellers' experience of the quality and ambience of a journey is also relevant here. Journey quality can be affected, positively or negatively, by travellers themselves and by network providers and operators. Examples are the social environment within the network and the condition and cleanliness of public transport vehicles, provision, design and quality of en-route facilities, and information for road users (Department for Transport [DfT], 2003a). Secondly, walking and cycling, as a form of physical activity, have some positive impacts on health, which include reducing the mortality and morbidity risk from cardiovascular diseases (see WHO, 2007 for an overview). Thirdly, transport strategies or plans may also affect the level of security for road users and public transport passengers, for example, the lighting in passenger areas at night when the facility is open, provision of emergency phones, etc. (DfT, 2003b).

\section{The Treatment of Social Impacts in Transport Appraisal in the Netherlands and the United Kingdom}

\section{The Dutch and the UK Approach to Transport Appraisal}

This section will examine the inclusion of social impacts in transport policy appraisal guidelines in the Netherlands and the United Kingdom. As explained above, these countries serve as examples because they have comprehensive guidelines for transport policy appraisal, and much practical experience in applying them. However, this does not necessarily mean being at the forefront of understanding the nature of social impacts and how best to address them.

The Dutch government requires that an infrastructure appraisal guideline (Overview Impacts Infrastructure, 'OEI' in Dutch) is applied to evaluate proposed major infrastructural plans, funded by the national government. The OEI guidance was established in 2000 (Eijgenraam et al., 2000), and supplements were published in 2004 (Ministry of Transport, Public Works and Water Management, 2004). To date, more than ten major infrastructure projects have been evaluated (see Annema et al., 2007 for a review). The OEI guideline prescribes a cost-benefit analysis and, whenever possible, a systematic evaluation of all possible effects of an investment project, including awarding them a monetary value. Detailed directions for the measurement or valuation of effects are not provided; however, some recommendations are given. If monetary valuation is not possible, quantitative or qualitative effects are to be described. The guideline categorizes effects into direct effects (e.g. travel time benefits and reliability benefits), indirect effects (e.g. better functioning of housing and labour markets, and international redistribution) and external effects (e.g. traffic safety and environmental impacts). All impacts of 
project alternatives are to be compared to the reference situation and recorded in a one-page summary table using a fixed format, including both quantitative effects and monetized values, in terms of present value. The summary table records: (1) all direct, indirect and external benefits; (2) investment, exploitation and maintenance costs; and (3) an overall 'value-for-money' score in terms of a benefit/cost ratio of all monetized effects and qualitative scores of non-monetized items (in terms of plus, minus and/or question marks for unknown effects). Furthermore, the guideline requires that attention is paid to the distribution of direct, indirect and external impacts among population groups and regions; impacts are to be reported in the summary of the report and added to the summary table.

In the UK, the Department for Transport uses the Transport Analysis Guidance as a requirement for all projects/studies that require government approval. The current guidance and future updates are published on a website (http:// www.webtag.org.uk). The website provides detailed guidelines for the appraisal of transport projects, and wider advice on scoping and carrying out transport studies. For projects/studies that do not require government approval, TAG serves as a best-practice guide. The guidance originates from the New Approach to Appraisal (NATA), launched in 1998, and is now the basis for the appraisal of, for example, multi-modal studies, Highways Agency road schemes, and major road and public transport schemes in Local Transport Plans. The appraisal framework is made up of four parts (DfT, 2004). The first part consists of an Appraisal Summary Table (AST), which is a one-page tabular summary of the main impacts of a transport solution. Impacts are recorded according to five main objectives: environment, safety, economy, accessibility and integration. The AST includes both qualitative and quantitative information, the latter of which is expressed in monetary terms or other units. Monetized items currently include direct effects (travel time benefits, providers' revenues and costs), accidents, carbon emissions and noise impacts, and are input for a partial CBA to estimate a benefit/cost ratio, which, in turn, is input for an MCA. However, no weighting information is provided, and decision-makers must apply their own judgement when weighing the impacts to reach an assessment of the overall monetary value of a proposal. Thus, it can be argued that the approach is no MCA in its purest form (Odgaard et al., 2005). The UK government is currently moving towards a pure CBA, in which more impacts (e.g. local air quality) are to be valued (DfT, 2006a). In contrast to the Dutch OEI guidance, the summary table does not include an overall score of options or alternatives. The second part of the WebTAG appraisal framework is an assessment of the degree to which the local and regional objectives of the study would be achieved. The third part of the framework is an assessment of the extent to which the identified problems would be ameliorated by the achieved option or options. The fourth, and final, part of the appraisal framework contains advice for conducting supporting analyses of distribution and equity, affordability and financial sustainability, along with practicality and public acceptability.

As practical applications of the appraisal guidelines may differ from the guidelines, the inclusion of social impacts in the OEI and WebTAG guidance will be examined, along with a recent application. The Amsterdam Airport Schiphol-Amsterdam-Almere corridor appraisal study (Decisio, 2005; Ministry of Transport, Public Works and Water Management, 2006) is a recent example of a Dutch transport infrastructure appraisal study. The decision-making process 
was subject to a heavy public debate, and a fairly extensive appraisal study was conducted. The appraisal study included strategic and detailed transport modelling and noise and air quality modelling, to quantify the impacts of different options for reducing congestion and increasing the road capacity of motorways connecting Amsterdam Airport Schiphol and Amsterdam to Almere, a new town, $30 \mathrm{~km}$ east of Amsterdam. Options included road pricing, above ground and underground expansion of existing orbital motorways, and the construction of a new motorway through a nature park.

The London to Ipswich Multi-Modal Study (Mott MacDonald, 2002) is a major example of such a study. The 22 multi-modal studies, conducted in the UK so far, vary considerably in size and complexity. Larger studies cover major strategic transport networks. Smaller studies focus on more specific and localized problems. The London to Ipswich study was quite an extensive study, involving a land-use transport interaction model, and additional detailed highway and rail models, to examine the impacts of separate and combined road and rail transport investments in the London to Ipswich corridor, about $100 \mathrm{~km}$ north-east of London. The studies followed the Guidance on the Methodology for Multi-Modal Studies (GOMMMS), which was superseded in 2004 by the WebTAG framework. The methodology used in WebTAG is the same as in GOMMMS, except for a number of revisions and supplements: guidance on noise, for example, moved from quantitative measurement to monetary valuation in 2006 (DfT, 2006a). It has to be noted that the two applications are just illustrations; conclusions based only on these two applications cannot be generalized to all. Annema et al. (2007) and the Commission for Integrated Transport (2004) have indicated that not all appraisals based on OEI and WebTAG are carried out to a consistent standard.

As already noted in the introduction, transport appraisal is typically carried out as part of an overall decision-making process, which also involves consultation and participation of the general public. Both the Amsterdam Airport Schiphol to Almere and London to Ipswich studies involved providing information to, and consultation with, the local residents and businesses. For example, surveys were conducted in both studies to examine public opinions on transport problems in the study area, and on the examined project alternatives. Although public involvement is important, it may contribute to better assessments, better decisions and greater acceptance of projects-this article focuses on appraisal frameworks only.

\section{Comparison of the Assessment Methods and the Typology of Social Impacts}

In studying the treatment of social impacts (as categorized in Table 2), the impact that is included in the Dutch and the UK transport appraisal guidances is identified, as well as which type of analysis is prescribed. Comparing these two countries, this article applies the steps of Odgaard et al. (2005), who have described national appraisal practices in EU Member States; they distinguish five types of analysis:

(1) Cost-benefit analysis: quantified effects are assigned a monetary value and included in an overall economic appraisal of the total value of the project in monetary terms.

(2) MCA: quantified effects are included in an overall project appraisal by assigning non-monetary weights to the individual effects. 
(3) Quantitative measurements: effects are estimated in physical units or numbers and not weighed to allow an aggregation of effects to a single criterion.

(4) Qualitative assessment: effects are classified into ranked categories using standard criteria or no systematic appraisal methods are used.

(5) No information/not covered.

A very broad definition of social impacts is used and, therefore, the different views on what should be included as a social impact and what not is sidestepped. For example, option values can be seen as economic impacts, but are essentially also social ones (and are defined as such in this article). The same goes for safety and some environmental impacts, such as health impacts due to emissions.

Table 2 displays the treatment of social impacts in the Dutch and the UK appraisal frameworks, and gives examples of applications from both countries.

A number of general observations can be made from Table 2. The table shows that both the current Dutch and, in particular, the UK transport appraisal guidance, pay attention to a wide array of potential social impacts, but do not cover the full spectrum as identified in the literature. A small number of impacts is addressed through quantitative measurements and assigned a monetary value, for instance, traffic casualties, noise nuisance and air pollution. These impacts are typically included in CBAs and EIAs, forming the basis for both guidances. Moreover, the table clearly illustrates differences in the treatment and measurement of social impacts between the Dutch and the UK guidances. That is, OEI focuses on quantitative measurements and monetary valuation of impacts, whereas WebTAG covers a much wider range of social impacts through qualitative assessments, scoring impacts in terms of 'neutral', 'slightly beneficial', 'largely beneficial' or 'adverse'. However, the types of analyses and assessments employed in the Amsterdam to Almere study in the Netherlands and the London to Ipswich study in the UK are surprisingly similar, given the differences in guidance. Both studies treated several social impacts through quantitative and/or qualitative analysis.

There are several possible explanations for the current treatment of social impacts in the Dutch and the UK appraisal guidances and for their applications. Firstly, there are problems with the identification and measurement of a number of social impacts in the appraisal of transport investments. The literature identifies social impacts associated with transport systems, but their importance differs in the appraisal of individual transport infrastructure plans or projects. Several impacts, such as safety perceptions, cultural diversity and averting behaviour, are more likely to be associated with general transport trends or major transport system changes (e.g. opening of transport facilities which connect remote areas to urbanized areas), than with transport improvements in regions or countries with already well-developed transport networks. Moreover, there are difficulties in translating theoretical concepts from social sciences to measurable indicators and empirical evidence. In particular, much research has been conducted on social cohesion and related concepts in the social science literature. However, in the transport field these concepts lack a clear definition of operation and lack evidence on how a transport investment or policy may affect people's level of participation in activities or the number of neighbourhood contacts (see Forckenbrock et al., 2001; Centre for Transport Studies, 2006). The translation of transport changes into health impacts is also problematic due to complex causal relationships. Noise nuisance and local air pollution are, for 
82 K. T. Geurs et al.

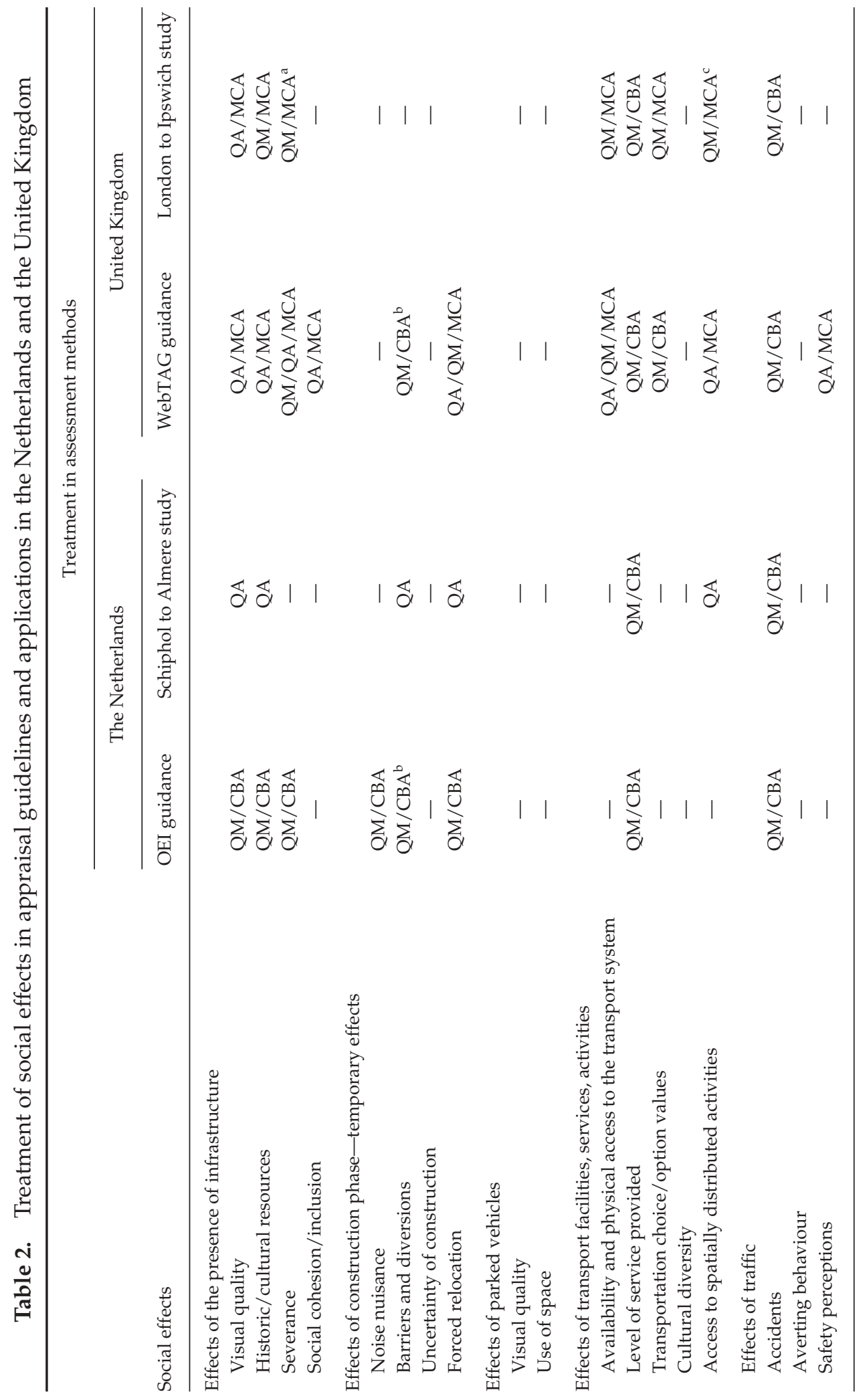




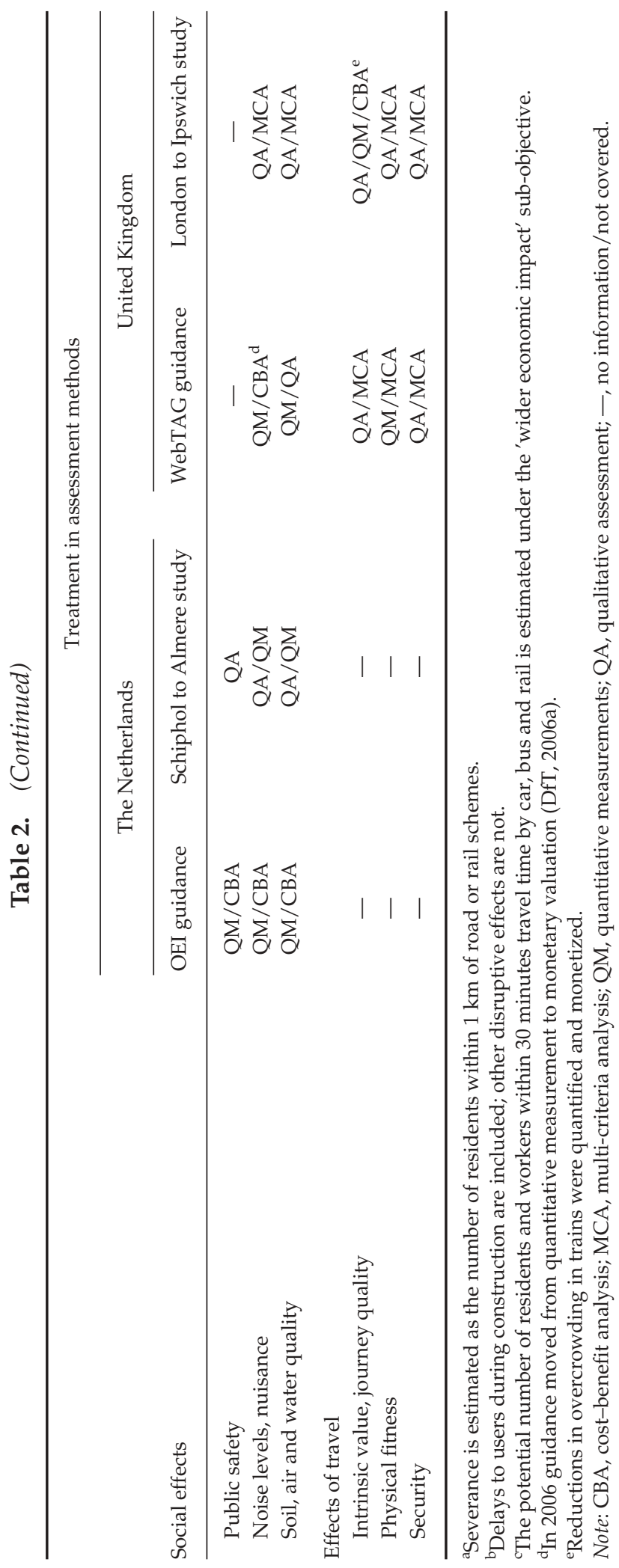


example, included in the appraisal guidelines but not translated into health impacts in terms of, for example, mortality and morbidity.

Secondly, the identification and treatment of impacts in OEI and WebTAG are also partly explained by the context in which they have been developed. The Dutch and the UK guidances are geared towards appraising major national and regional transport investments, which require approval and funding from the national government. Therefore, little attention is being paid to local effects such as those concerning parked vehicles. Furthermore, OEI and WebTAG focus on modelling techniques as a research method, and provide little guidance on other research methods to examine social impacts of transport investments. However, WebTAG does include specific guidance on the use of social research techniques (e.g. surveys) to assess the social and distributional impacts of road pricing schemes (DfT, 2006b). Differences between the Dutch and the UK national appraisal guidance are also the result of differences in the national tradition of project appraisal. WebTAG follows a more objective-led approach, whereas OEI follows a stricter welfare economic perspective (CBA). As a result, the Dutch evaluation framework treats accessibility impacts only partially; the framework focuses on travel time savings and lacks attention for the physical access to transport systems, transport option values and access to spatially distributed key services and activities. Moreover, OEI does not address social exclusion, or effects and valuations of travelling (e.g. journey ambience and physical fitness). Some of these differences in guidance are also induced by differences in transport policy, for example, social exclusion is a major policy issue in the UK but not in the Netherlands.

The Amsterdam to Almere study in the Netherlands and the London to Ipswich study in the UK have based the appraisal of effects on the output of landuse, transport and environmental models or other readily available data. No additional primary research or valuation studies have been conducted. To the authors' knowledge, this is also the case for all other applications of the OEI and WebTAG guidance, to date. This may explain the lack of attention on impacts not captured by standard modelling techniques, and for which data are often not readily available (e.g. temporary impacts during the construction phase of transport infrastructure); perceptions of the physical environment (e.g. cars parked on the street); psychological impacts (e.g. post-traumatic stress due to traffic accidents); and effects of travel (e.g. physical fitness). The difficulty of appraisal was also noted in a review of the UK multi-modal studies (Bates et al., 2004). In it, consultants reported problems with data collection and with applying analytical models to quantify, for example, visual quality effects (landscape and townscape sub-objectives), historical resources (heritage sub-objective), effects of travel (physical fitness, security, journey ambience), option values and access to the transport system.

An important element in the analysis of social impacts is the treatment of differences between population groups and their valuation in terms of social (in)justice. Both OEI and WebTAG provide little guidance on the evaluation of the distribution of impacts among population groups. OEI and WebTAG require a disaggregation of costs and benefits across relevant economic interest groups in the AST, such as users and transport system operators. Furthermore, supporting analysis is suggested, which is to be reported outside the summary table. OEI provides no further guidance on distributional analysis. To date, WebTAG provides some hints about the kinds of distributional analyses that could be 
carried out of each impact included in the AST, such as an analysis of the geographical distribution of effects (e.g. between rural and urban areas) and the distributional analysis across population groups (e.g. gender and race). WebTAG does, however, as noted earlier, provide guidance on requirements for measuring social and distributional impacts, using social research methods when projects include road pricing schemes (DfT, 2006b). Moreover, OEI and WebTAG provide no specific guidance on the analysis of cumulative distributional social impacts, for instance, cumulative effects of high traffic and pollution levels affecting low-income or other disadvantaged populations. Therefore, the Amsterdam Airport Schiphol to Almere study in the Netherlands and the London to Ipswich study in the UK, probably, pay little or no explicit attention to the distribution or accumulation of effects for specific population segments. WebTAG does provide guidance for the treatment of the accumulation of environmental impacts (e.g. impacts on landscape, biodiversity and the water environment).

OEI and WebTAG also provide no guidance for the inclusion of social justice or alternative weighting systems, which would allow testing the robustness of decisions, in terms of justice and acceptability. Economic theory offers little help with the choice of weighting system (for a discussion see also Eijgenraam et al., 2000; Commission for Integrated Transport, 2004). OEI follows the CBA principles; thus, a 'utilitarian' approach is taken, where justice is done when the total amount of utility is maximized, regardless of the distribution. However, several alternative theories or approaches to justice are documented in the literature, which can be used as input in the decision-making process, for example, an equal shares or an egalitarian approach (Khisty, 1996). WebTAG does not offer alternative weighting systems either, but these are rarely used in transport policy appraisal (see PROPOLIS, 2003 for an exception). Both applications studied in this article (and, to the authors' knowledge, all other applications to date) have not examined alternative weighting systems.

\section{Conclusions}

Transport policy appraisal should ideally cover three dimensions of sustainability-economic, ecological and social. However, social impact appraisal often receives little attention, despite the fact that these impacts, particularly the distribution of 'costs' and 'benefits' of a transport policy across population groups and regions, often receive much public and political attention in decision-making processes. This article firstly presented a theoretical framework, describing the relationships between determinants of social impacts of transport, and provided a definition and categorization of social impacts. Secondly, the article reviewed the state of the practice of national transport appraisal in the Netherlands and the United Kingdom.

It can be concluded that the UK transport appraisal guidance (WebTAG) includes a much broader spectrum of social impacts than the Dutch appraisal guidance (OEI), but it does not cover the full range of potential social impacts as identified in the literature. The Dutch guidance focuses on quantitative measurements and monetary valuation of impacts, whereas the UK guidance deals with an important range of social impacts through qualitative assessments. Both guidances assign a monetary value to a few well-known social impacts, such as traffic safety and delays caused by road construction. A number of potentially 
relevant social impacts are not sufficiently dealt with in the guidances, particularly temporary impacts of transport investments, health impacts and social cohesion effects. In addition, the Dutch evaluation framework only partially deals with accessibility impacts and does not deal with the effects and valuations of travelling itself (in addition to travel time savings). The current Dutch and the UK appraisal guidances also provide little guidance for the evaluation of the distribution of impacts across population groups, the accumulation of impacts on these groups, and social justice assessments. As a result of which, practical applications also pay little attention to these impacts.

The current article also examined a typical application of each guidance in both countries-the Amsterdam to Almere study in the Netherlands and the London to Ipswich study in the UK. The types of analyses and assessments employed in these practical applications were surprisingly similar, given the differences in guidance. Both studies treated several social impacts through quantitative and/or qualitative analysis. Clearly, in practice, several social impacts are difficult to quantify or monetize due to problems with time and budget restraints, data collection and a lack of research methods and/or appropriate evaluation tools.

All in all, it can be concluded that there is still a long way to go before social impacts of transport projects are included in appraisals in a mature way that allows comparing them to economic and-to a lesser extent-ecological effects. To improve current practice, several directions for further research can be identified.

\section{Discussion and Directions for Further Research}

The conclusions and other elements in this research article may well be subject to further discussion and can be used to derive subjects for further research. The first issue for discussion is the validity of the identification of social impacts as a separate entity. The distinction between social, ecological and mainly economic impacts is often opaque, and questions on mutual exclusivity remain. One can argue the importance of this debate, but even listing examples of social impacts reveals many important issues. Regardless of whether these examples are called social impacts or something else, they should be identified in policy appraisal.

Secondly, in describing which social impacts are identified in the state of the practice of appraisal guidelines, and which type of analysis is suggested to measure the impacts, the article's main aim was to find voids in appraisal guidelines. The methodological soundness of the impact assessments was not evaluated. There are, for example, difficulties in translating theoretical concepts from social sciences to measurable indicators and empirical evidence, and difficulties and uncertainties when translating transport changes into health impacts via doseeffect relationships. This leads to the first major direction for further research, which is to conduct research to improve the methodological soundness of social impact assessments. Key issues are the definition of indicators and how to assess them in a specific context, and the harmonization of the valuation of social impacts.

A third major direction of research worth pursuing is examination of the relative importance of all indicators of social impacts for different types of projects and plans; the question being: which indicators are the most important for which appraisals? For example, if the focus of appraisal guidelines is on national impacts, local impacts might become underexposed. Focussing on indicators that really matter may improve the ability of decision-makers to judge options. To determine the importance of social impacts, more research into the 
measurement of social impacts is necessary, including the development of better conceptual models and more advanced methods of research. It has been shown that some theoretical concepts have not been translated very well into the appraisal guidelines. Furthermore, methods may include panel data research in addition to cross-section data-based research, showing the impacts of changes in determinants on social impact indicator(s). These methods may also include more advanced research techniques, such as structural equation modelling and multi-level regression models. For the conceptual models, it is recommended to research self-selection. When researching health impacts, the possibility must be considered that persons who are more sensitive to some social effects (those with respiratory disorders, for example) will avoid residential locations near busy roads and motorways more often than the average person would. If this is true, the results, as found in empirical studies, might underestimate the effects of living near busy roads and motorways. Moreover, research on the relevance of social impacts would need to address distributional aspects and the accumulation of social impacts across population groups. Not all groups, for example, differentiated by income, gender, race, ethnicity, age, geographical region, etc., will be affected by specific transport policies or investments. Finally, research can also be directed at examining which effects policymakers would want to be included in appraisal methods and how this should be done.

The fourth direction of research is to improve the potential role of social impacts in decision-making. Decision-makers may find it difficult that some social impacts are quantified and monetized, while others are not. It can be argued that integrating social impacts into a CBA can be a great advantage, as this could lead to a more consistent and integral comparison of policy options. Placing monetary value on social impacts could make the role of decision-makers easier, as they would have to make fewer trade-offs. However, for several social impacts considerable research would be needed to make this possible-if it is possible at all. Moreover, some countries have moved away from monetizing specific social effects. For example, Denmark and Sweden have moved away from a quantified and monetized effect to severance (for instance, based on time lost by pedestrians when crossing roads), as this would make assessments less transparent by simplifying a number of complex effects into a single number and ultimately a monetary value (Tomlinson and James, 2005). Furthermore, CBA is not well placed to address the distribution of costs and benefits or to assess decisions in terms of justice and acceptability. As noted earlier, CBA assumes justice is done when the total amount of utility is maximized, regardless of the distribution. Alternative approaches to justice are documented in the literature, which would allow testing the robustness of decisions in terms of justice, and aiding the assessment of acceptability of transport policies. Few appraisal studies (see PROPOLIS, 2003, for example) have experimented with offering decision-makers alternative weighting schemes based on social justice theories within an MCA framework. Further research is necessary to examine whether alternative weighting systems can be helpful as input in the decision-making process.

\section{Acknowledgements}

The authors thank Karen Lucas, Transport Studies Group, University of Westminster, and three anonymous reviewers for their useful comments on earlier versions of this article. 


\section{Notes}

1. According to social psychological and micro-economic theories (e.g. Ajzen, 1991), perceptions, preferences (related to utility) and attitudes (which are opinions on objects or subjects that are stable over a longer period of time) influence a subject's behaviour. In this context it is impossible to view perceptions, preferences and behaviour as distinct elements. These are regarded as mutually dependent.

2. Lichfield (1996) presented an analogous chain in connection with Community Impact Analysis, in which he coupled activities and effects to impacts on distinct community sectors (or groups in the community).

\section{References}

Adams, J. (2000) The social implications of hypermobility. Speculations about the social consequences of the OECD Scenarios for Environmentally Sustainable Transport and Business-As-Usual Trend Projections. Paper presented at the Ottawa Workshop (ENV/EPOC/PPC/T(99)3/FINAL), OECD, Paris, January 2000.

Agran, P. F., Winn, D. G., Anderson, C. L., Tran, C. and Del Valle, C. P. (1996) The role of the physical and traffic environment in child pedestrian injuries, Pediatrics, 98(6), pp. 1096-1103.

Ajzen, I. (1991) The theory of planned behaviour, Organisational Behaviour and Human Decision Processes, 50(2), pp. 179-211.

Annema, J. A., Koopmans, C. and Van Wee, B. (2007) Evaluating transport infrastructure investments: the Dutch experience with a standardised approach, Transport Reviews, 27(2), pp. 25-150.

Appleyard, D. (1981) Livable Streets, Protected Neighborhoods (Berkeley, CA: University of California Press).

Appleyard, D. (1986) Evaluating the social and environmental impacts of transport investment, in: E. De Boer (Ed.) Transport Sociology, pp. 51-67 (Oxford: Pergamon).

Bates, J., Mackie, P., Nellthorp, J. and Forster, D. (2004) Evaluation of the Multi-Modal Study Process. Modelling and Appraisal (London: DfT).

Burton, E. (2000) The compact city: just or just compact? A preliminary analysis, Urban Studies, 37(11), 1969-2006.

Centre for Transport Studies (2006) Social Inclusion: Transport Aspects (UG320) (London/Leeds: Centre for Transport Studies, Imperial College/Mott MacDonald, Institute for Transport Studies, University of Leeds).

Choo, S., Collantes, G. O. and Mokhtarian, P. L. (2005) Wanting to travel, more or less: exploring the determinants of the deficit and surfeit of personal travel, Transportation, 32(2), pp. 135-164.

Commission for Integrated Transport (2004) A Review of Transport Appraisal. Advice from the Commission for Integrated Transport (London: Author).

De Boer, E. (1986) Transport sociology: social aspects of transport planning, in: E. de Boer (Ed.) Transport Sociology, pp. 7-18 (Oxford: Pergamon).

Decisio (2005) Kosten-baten analyse op hoofdlijnen voor de planstudie Schiphol-A'am-Almere. Eindrapport [Cost-Benefit Analysis of the Amsterdam Airport Schiphol-Amsterdam-Almere Corridor] (Amsterdam: Author).

DfT (2003a) The Journey Ambience Sub-Objective. TAG Unit 3.3.13 (London: Author).

DfT (2003b) The Security Sub-Objective. TAG Unit 3.4.2 (London: Author).

DfT (2004) The Appraisal Process. TAG Unit 2.5 (London: Author).

DfT (2006a) Cost Benefit Analysis. TAG Unit 3.5.4 (London: Author).

DfT (2006b) Measuring the Social and Distributional Impacts of Road Pricing Schemes. TAG Unit 3.12.4 (London: Author).

Eijgenraam, C. J. J., Koopmans, C. C., Tang, P. J. G. and Verster, A. C. P. (2000) Evaluation of Infrastructural Projects. Guide for Cost-Benefit Analysis. Part I (Main Report) and Part II (Capita Selecta) (The Hague/ Rotterdam: CPB Netherlands Bureau for Economic Policy Analysis/Netherlands Economic Institute).

Finsterbusch, K. (1980) Understanding Social Impacts: Assessing the Effects of Public Projects (London: Sage).

Fischer, T. B. (1999) Comparative analysis of environmental and socio-economic impacts in SEA for transport related policies, plans, and programs, Environmental Impact Assessment Review, 19(3), pp. 275-303.

Forckenbrock, D. J., Benshoff, S. and Weisbrod, G. E. (2001) Assessing the Social and Economic Effects of Transportation Projects. (Iowa City, IA/Boston, MA: University of Iowa/Economic Development Research Group). 
Geurs, K. T., Haaijer, R. and Van Wee, B. (2006) Option value of public transport: methodology for measurement and case study for regional rail links in the Netherlands, Transport Reviews, 26(5), pp. 613-643.

Geurs, K. T. and Van Wee, B. (2004a) Land-use/transport interaction models as tools for sustainability impact assessments of transport investments: review and research directions, European Journal of Transport and Infrastructure Research, 4(3), pp. 333-355.

Geurs, K. T. and Van Wee, B. (2004b) Accessibility evaluation of land-use and transport strategies: review and research directions, Journal of Transport Geography, 12, pp. 127-140.

Hüttenmoser, M. and Meierhofer, M. (1995) Children and their living surroundings: empirical investigations into the significance of living surroundings for the everyday life and development of children, Children's Environments, 12(4), pp. 1-17.

IAIA (2003) Social Impact Assessment: International Principles. Special Publication Series No. 2. International Association for Impact Assessment (Fargo, ND: Author). Available at: http:// www.iaia.org/modx/assets/files/SP2.pdf (accessed 7 May 2008).

Jain, J. and Lyons, G. (2008) The gift of travel time, Journal of Transport Geography, 16(2), pp. 81-89.

James, E., Millington, A. and Tomlinson, P. (2005) Understanding Community Severance I: Views of Practitioners and Communities (Wokingham: TRL).

Jones, P. (2001) Addressing equity concerns in relation to road user charging. CUPID Position Paper CUPID-PROGRESS Workshop, Trondheim.

Khisty, C. J. (1996) Operationalizing concepts of equity for public project investments, Transportation Research Record, 1559, pp. 94-99.

Laird, J., Batley, R., Nash, C. and Geurs, K. T. (2006) Option Values, Non-Use Values and Transport Appraisal (Leeds: Institute for Transport Studies, University of Leeds).

Lichfield, N. (1996) Community Impact Evaluation (London: UCL Press).

Lichfield, N. and Lichfield, D. (1992) The integration of environmental assessment and development planning, part 2: Prospect Park, Hillingdon, Project Appraisal, 7(3), pp. 175-185.

Litman, T. (2002) Evaluating transportation equity, World Transport Policy E Practice, 8(2), pp. 50-65.

Lucas, K. (2006) Providing transport for social inclusion within a framework for environmental justice in the UK, Transportation Research Part A: Policy and Practice, 40(10), pp. 801-809.

Marx, A. (2002) Uncertainty and social impacts-a case study of a Belgian village, Environmental Impact Assessment Review, 22(1), pp. 79-96.

McDonald, N. C. (2007) Travel and the social environment: evidence from Alameda County, California, Transportation Research Part D: Transport and Environment, 12(1), pp. 53-63.

McMillan, T. E. (2007) The relative influence of urban form on a child's travel mode to school, Transportation Research Part A: Policy and Practice, 41(1), pp. 69-79.

Ministry of Transport, Public Works and Water Management (2004) Aanvullingen op de leidraad overzicht effecten infrastructuur [Supplements to the Appraisal Guidance] (The Hague: Author).

Ministry of Transport, Public Works and Water Management (2006) Overzichtsrapportage Planstudie Schiphol-Amsterdam-Almere [Overview report Schiphol-Amsterdam-Almere study] (The Hague: Author).

Mott MacDonald (2002) London to Ipswich Multi-Modal Study. LOIS Final Report (Croydon: Author). Available at: http://www.eera.gov.uk/category.asp?cat=291\&id=SXD218-A77F5587 (accessed 28 December 2006).

Odgaard, T., Kelly, C. and Laird, J. (2005) HEATCO. Developing Harmonised European Approach for Transport Costing and Project Assessment. Deliverable 1: Current Practice in Project Appraisal in Europe. Analysis of Country Reports (Stuttgart: IER).

PROPOLIS (2003) Planning and Research of Policies for Land Use and Transport for Increasing Urban Sustainability (PROPOLIS). Final Report (Helsinki: LT Consultants).

Redmond, L. S. and Mokhtarian, P. L. (2001) The positive utility of the commute: modeling ideal commute time and relative desired commute amount, Transportation, 28(2), pp. 179-205.

Serageldin, I. and Steer, A. (1994) Making Development Sustainable: From Concepts to Action (Washington, DC: World Bank).

Social Exclusion Unit (2003) Making the Connections: Final Report on Transport and Social Exclusion (London: Author).

Song, Y., Gee, G. C., Fan, Y. and Takeuchi, D. T. (2007) Do physical neighborhood characteristics matter in predicting traffic stress and health outcomes? Transportation Research Part F: Traffic Psychology and Behaviour, 10(2), pp. 164-176.

Stephens, C. and Bullock, S. (2002) Environmental justice: an issue for the health of the children of Europe and the world, Environmental Issue Report: Children's Health and Environment, 29, pp. 190-196. 
Tavasszy, L., Jonkhoff, W., Burgess, A., Rustenburg, M. and Hunt, A. (2005) HEATCO. Developing Harmonised European Approach for Transport Costing and Project Assessment. Deliverable 3. Key Issues in the Development of Harmonised Guidelines for Project Assessment and Transport Costing (Delft: TNO).

Tomlinson, P. and James, E. (2005) Understanding Community Severance: Part II: Monetisation of Severance Impacts. Final Report (Wokingham: TRL).

Van der Houwen, K., Goossen, J. and Veling, I. (2004) Reisgedrag kinderen basisschool [Travel Behaviour of Primary School Children] (Veenendaal: Traffic Test).

Van Wee, B. and Van der Hoorn, T. (2002) Effects of office relocations to public transport nodal points on passenger mobility, in: E. Stern, I. Salomon and P. H. L. Bovy (Eds) Travel Behaviour. Spatial Patterns, Congestion and Modelling, pp. 265-279. (Cheltenham: Edward Elgar).

WHO (2000) Transport, Environment and Health (Copenhagen: Author).

WHO (2007) Economic Assessment of Transport Infrastructure and Policies. Methodological Guidance on the Economic Appraisal of Health Effects Related to Walking and Cycling (Copenhagen: Author). 